\title{
EV Charging Analysis Based on the National Travel Surveys of the Nordic Area
}

\author{
Liu, Zhaoxi; Wu, Qiuwei
}

Published in:

Proceedings of 2014 IEEE Power \& Energy Society General Meeting

Link to article, DOI:

10.1109/PESGM.2014.6939315

Publication date:

2014

Document Version

Early version, also known as pre-print

Link back to DTU Orbit

Citation (APA):

Liu, Z., \& Wu, Q. (2014). EV Charging Analysis Based on the National Travel Surveys of the Nordic Area. In Proceedings of 2014 IEEE Power \& Energy Society General Meeting IEEE.

https://doi.org/10.1109/PESGM.2014.6939315

\section{General rights}

Copyright and moral rights for the publications made accessible in the public portal are retained by the authors and/or other copyright owners and it is a condition of accessing publications that users recognise and abide by the legal requirements associated with these rights.

- Users may download and print one copy of any publication from the public portal for the purpose of private study or research.

- You may not further distribute the material or use it for any profit-making activity or commercial gain

- You may freely distribute the URL identifying the publication in the public portal 


\title{
EV Charging Analysis Based on the National Travel Surveys of the Nordic Area
}

\author{
Zhaoxi Liu, Qiuwei Wu \\ Centre for Electric Power and Energy (CEE), Department of Electrical Engineering \\ Technical University of Denmark \\ Kgs. Lyngby, Denmark \\ E-mail: qw@elektro.dtu.dk
}

\begin{abstract}
This paper presents the charging demand profiles of electric vehicles (EVs) based on the National Travel Surveys of the Nordic area. The EV charging analysis is carried out considering different types of charging patterns which are dumb charging, timed charging and spot price based charging. The driving behavior of the vehicles is studied through the National Travel Surveys of Denmark, Finland, Norway and Sweden. The features of the charging demand are discussed based on the results of the analysis. The study in this paper provides an estimation of the possible level and patterns of the EV charging demand in the Nordic area.
\end{abstract}

Index Terms-- charging, demand, electrical vehicle (EV), Nordic area

\section{INTRODUCTION}

The Nordic region including Denmark, Finland, Norway and Sweden has ambitions of achieving a sustainable energy system in a time perspective up to 2050. The development of renewable energy and low-carbon transport is viewed as an important way to achieve this goal [1], [2]. Electric vehicles (EVs), considered as a kind of distributed energy resources (DER), hold a potential to cope with the intermittency from the further utilization of renewable energy sources (RES) in the Nordic power grid. Furthermore, the worldwide concern about the greenhouse gas (GHG) emission and the independence from fossil fuel has motivated the development of EVs in the past few decades. With such impetus the study on the electrification of the transportation sector with largescale deployment of EVs shows strong necessity in the four mentioned Nordic countries.

With a large-scale deployment of EVs, the power and energy demand of EVs will have a large impact on the grid. The study of the impact of the EV charging on the grid started in 1970s [3]. A number of studies have been carried out on the topic ever since [4]-[12]. In most of the studies, either at a national scale or a regional scale, the energy consumption or the charging availability of the vehicles is often estimated without considering the real driving patterns of the vehicles.
Such assumptions might lead to inaccurate results in the EV charging analysis.

Regarding the Nordic area, charging demand of EVs is studied in different countries. The research in [13], [14] studies the charging demand based on the case of the Danish island of Bornholm. The study in [15] introduces the EV fleet integration in Bornholm with the Virtual Power Plant (VPP) concept. The study in [16] builds an optimal charging model according to the survey data of Western Denmark. The study in [17] estimates the charging cost of EVs in the Finnish context. The work in [18] studies the stochastic charging load of the plug-in hybrid electric vehicles (PHEVs) in Finland.

A general study regarding the charging demand of EVs based on the real driving behaviors for the Nordic area is missing at the moment. The work in [19] studies the driving patterns of Denmark based on the Danish National Travel Survey for the EV charging demand study. Following the work in [19], this paper presents an investigation of the charging demand of EVs based on the real driving behaviors in the Nordic area. The driving data from the National Travel Surveys of the four mentioned Nordic countries are used to determine the driving patterns of the vehicles. Based on the driving patterns of the vehicles, the average charging demand of EVs with different types of charging patterns is investigated. The EV charging demand and the impact of the charging rate are discussed according to the results of the EV charging analysis.

The paper is arranged as follows. The method of the EV charging analysis is introduced in Section II. The demand profiles of the EV charging in the Nordic area with different charging schemes are presented in Section III. The EV charging demand and the impact of the charging rate are discussed in Section IV. In the end, the conclusions are drawn.

\section{METHOD}

The method of the EV charging analysis consists of two parts - driving behavior analysis and EV charging patterns. 
The details of the driving behavior analysis and the EV charging patterns are described below.

\section{A. Driving Behavior Analysis}

In order to analyze the charging demand of EVs in the Nordic region, it is necessary to study the driving pattern of EVs in the area. Currently, it is difficult to obtain the driving pattern of EVs directly because there are few EVs on the road. However, with a high penetration level of EVs and sufficient support of charging facility, the driving pattern of EVs will show more or less the same as the conventional passenger cars when or if all the driving requirements are fulfilled. Therefore, it is feasible to use the driving pattern of conventional passenger cars in the Nordic area to estimate the driving pattern of EVs.

The driving pattern analysis is based on the data from the National Travel Surveys of Denmark, Finland, Norway and Sweden. The National Travel Surveys of the four countries are the most comprehensive data sources which have enough samples to represent the travel behaviors statistically in the corresponding Nordic country. Information of the driving behavior is extracted from the survey databases including the start and ending time of each trip, the driving destination of each trip as well as the driving distance of each trip. The information is used to form the driving patterns of each vehicle throughout the day and calculate the corresponding energy consumption of the driving activities. The charging availability of the vehicle is generated according to the driving and parking status of the vehicle along the time of the day. The status is known according to each observation of the travelling records in the database. Additionally, the parking place is also considered in the study. The EV charging availability is formed under two different conditions. The first condition assumes that the EVs can be charged whenever they are parked regardless of the parking place. The second condition assumes that the EVs can only be charged when they are parked at home. The difference in the charging availability has a notable impact in the demand patterns with a specific charging scheme, namely dumb charging.

\section{B. EV Charging Patterns}

Three types of charging patterns including dumb charging, timed charging and spot price based charging are analyzed in the study. Dumb charging refers to the uncontrolled charging of EVs. For the dumb charging cases, two scenarios are applied. The first scenario refers to the condition that the EVs can be charged whenever they are parked regardless of the parking place; the second scenario refers to the condition that the EVs can only be charged when they are parked at home. Timed charging refers to a scheduled charging at specific time periods when the conventional demands are low. The EVs are assumed to be charged after 21:00 pm of the day when they are parked. Spot price based charging refer to an optimal charging based on the expected electricity spot prices of the Nord pool electricity market. The objective is to minimize the charging cost with the energy requirement constraints of each individual vehicle respected.
At present, the EVs can be charged through single phase $230 \mathrm{~V}$ AC current, three phase $400 \mathrm{~V}$ AC current or external charger DC current for fast charging. Therefore, the charging rate of EVs can vary from a few $\mathrm{kW}$ to tens of $\mathrm{kW}$ according to the charging mode and the charging current. In the study of this paper, the charging is based on a typical charging rate of $3.68 \mathrm{~kW}$, which is corresponding to a $230 \mathrm{~V}$ AC single phase $16 \mathrm{~A}$ charging.

The time resolution of the EV charging analysis in this paper is one hour. The energy used per $\mathrm{km}$ for a home passenger car is typically between $120 \mathrm{Wh} / \mathrm{km}$ and $180 \mathrm{Wh} / \mathrm{km}$ [20]. For the charging analysis in this paper, an average rate of $150 \mathrm{Wh} / \mathrm{km}$ is used to calculate the energy consumption of the studied vehicles.

\section{Charging Profiles}

The EV charging profiles of the four Nordic countries are calculated with different charging patterns including dumb charging, timed charging and spot price based charging.

\section{A. Dumb Charging}

The results of the dumb charging all day are shown in Figure 1 and Figure 2. During the weekdays, the curves of all the four Nordic countries share a similar trend. With an ordinary charging rate, the average charging load of the EVs is not too high. There are two peaks in the EV charging load curves of dumb charging, one at 8-10 am in the morning and the other one at 5-8 pm in the evening when the latter one is higher in amplitude. The shape of load curve is consistent with people's driving requirement between home and work place. The average load curves show obvious differences between the weekdays and the weekends. The charging load on Saturdays and Sundays starts to rise rapidly late in the morning and the majority of the charging happens in the afternoon and evening when the people tend to arrive home. It shows a relatively higher demand on weekends in Finland. Such higher demand in Finland is mainly due to the more active driving behaviors and longer average driving distance for the trips to entertainment activities, restaurants and social evenings on weekends in Finland.

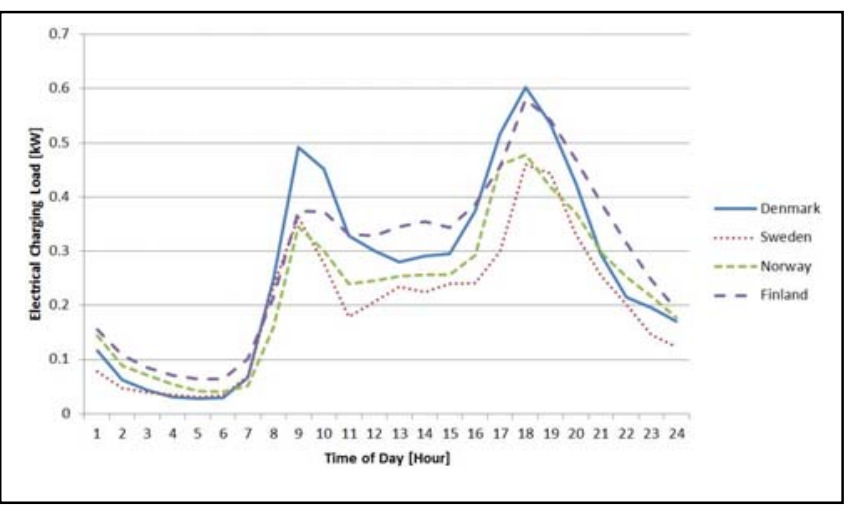

Figure 1. Average Load with Dumb Charging Anywhere on Weekdays. 


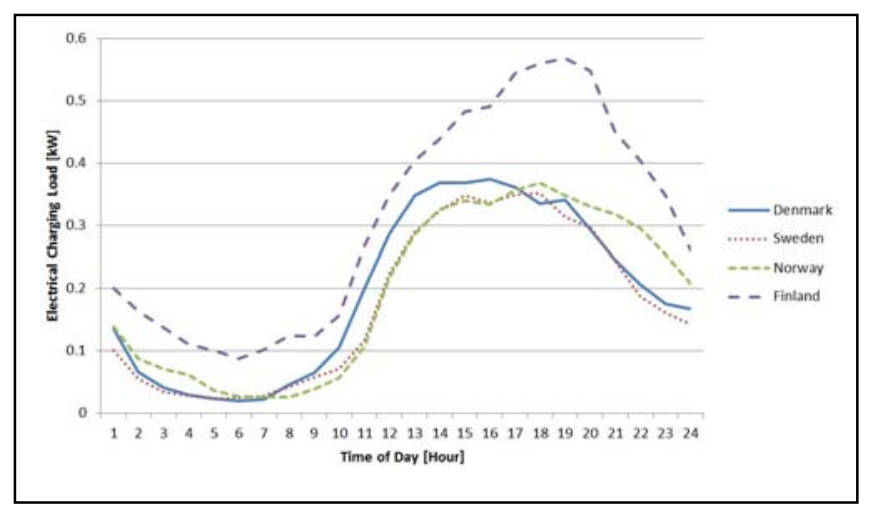

Figure 2. Average Load with Dumb Charging Anywhere on Weekends.

The average dumb charging load would be remarkably different if the EVs can only be charged at home. Figure 3 and Figure 4 show the results of the dumb charging if the EVs are charged during home parking on weekdays and on weekends, respectively. Different from the load of dumb charging all day, the load pattern of dumb charging at home has no spike in the morning on weekdays as they can only be charged after they reach home in the afternoon or evening. The charging load starts to rise from around $3 \mathrm{pm}$ in the afternoon and comes to the peak at 6-8 pm when the most of the people are reaching home from work. Without the load peak in the morning, the charging load converges in the evening. As a result, the peaks appear in the evening have higher amplitudes than the cases with dumb charging all day.

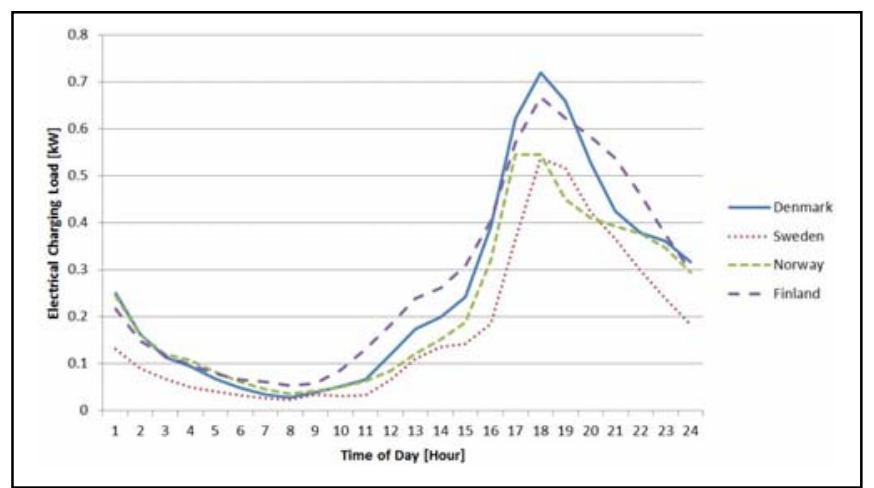

Figure 3. Average Load with Dumb Charging Homed on Weekdays.

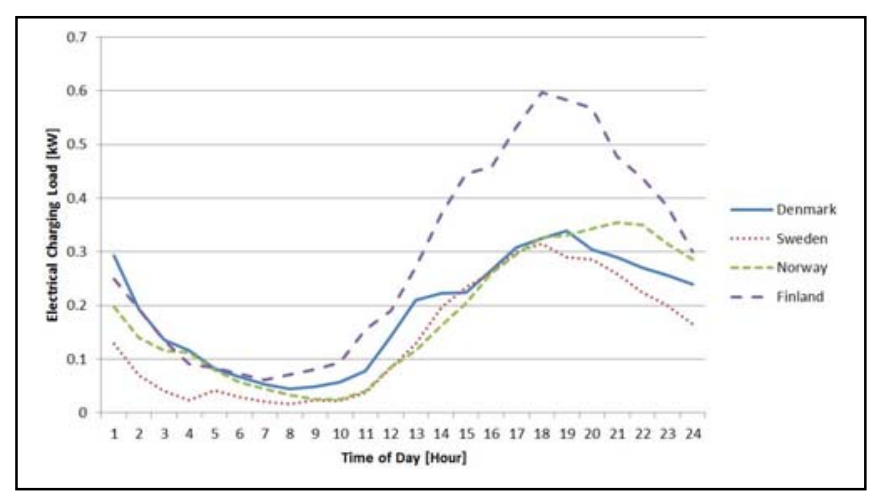

Figure 4. Average Load with Dumb Charging Homed on Weekends.
TABLE I shows the peak charging demand of the EVs with dumb charging in the Nordic area.

TABLE I. PEAK CHARGING DEMAND OF DUMB CHARgING

\begin{tabular}{|l|l|c|c|c|c|}
\hline \multicolumn{2}{|c|}{ Charging Schemes } & Denmark & Sweden & Norway & Finland \\
\hline \multirow{2}{*}{$\begin{array}{l}\text { Dumb } \\
\text { All Day }\end{array}$} & Weekdays & 0.60 & 0.46 & 0.48 & 0.58 \\
\cline { 2 - 6 } & Weekends & 0.37 & 0.35 & 0.37 & 0.57 \\
\hline \multirow{2}{*}{$\begin{array}{l}\text { Dumb } \\
\text { Home }\end{array}$} & Weekdays & 0.72 & 0.54 & 0.55 & 0.67 \\
\cline { 2 - 6 } & Weekends & 0.34 & 0.31 & 0.35 & 0.60 \\
\hline
\end{tabular}

The unit for the figures in the table is $\mathrm{kW}$.

\section{B. Timed Charging}

Figure 5 to Figure 6 show the results of the timed charging on weekdays and weekends, respectively. It is assumed that the EVs are charged after 21:00 pm when they are parked. The EV charging load of all the four Nordic countries shares similar patterns on both weekdays and weekends. The charging load converges at 9-11 pm when most of the cars start charging, and therefore forms a steep spike in this period.

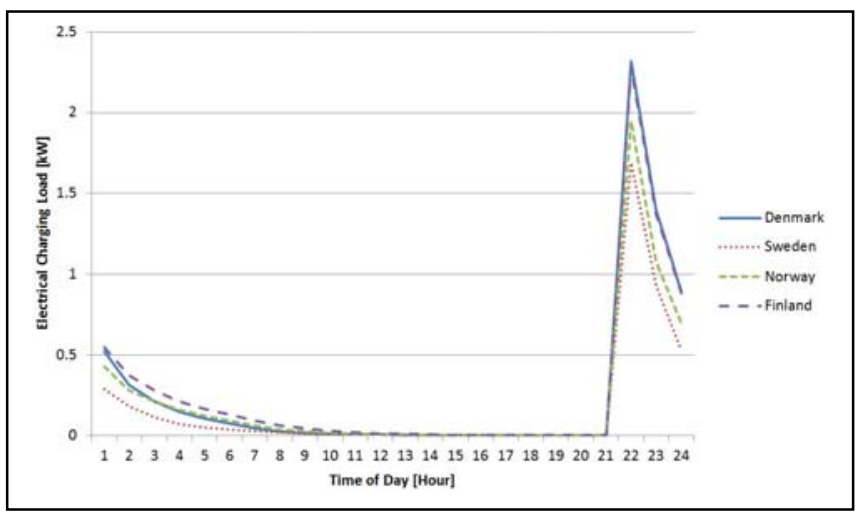

Figure 5. Average Load with Timed Charging on Weekdays.

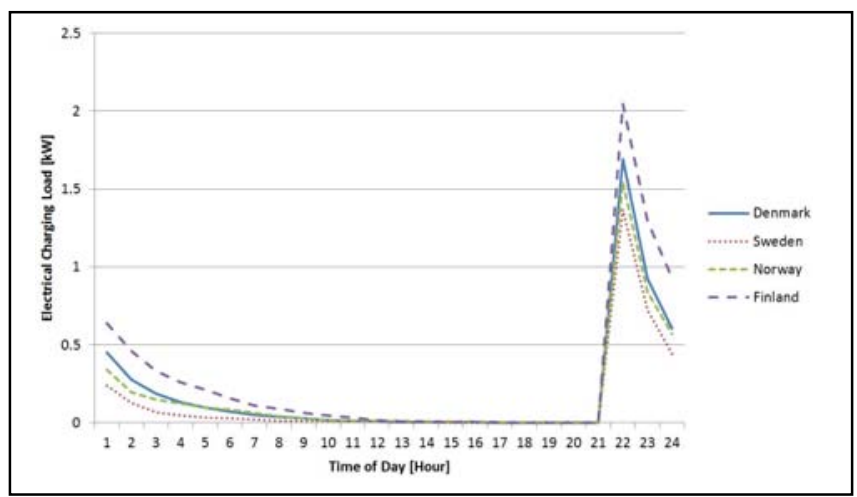

Figure 6. Average Load with Timed Charging on Weekends.

TABLE II shows the peak charging demand of the EVs with timed charging in the Nordic area.

TABLE II. PEAK CHARGING DEMAND OF TIMED CHARGING

\begin{tabular}{|c|c|c|c|c|}
\hline & Denmark & Sweden & Norway & Finland \\
\hline Weekdays & 2.32 & 1.69 & 1.95 & 2.28 \\
\hline Weekends & 1.69 & 1.37 & 1.54 & 2.05 \\
\hline
\end{tabular}

The unit for the figures in the table is $\mathrm{kW}$. 


\section{Spot Price Based Charging}

Figure 7 and Figure 8 show the results of the spot price based charging on weekdays and weekends, respectively. Similar to the case of timed charging, the EV charging load of all the four Nordic countries have similar patterns on both weekdays and weekends. As shown in the figures below, most of the charging happens at night during the hours with the low spot prices and leads to the high charging load in the corresponding time slots.

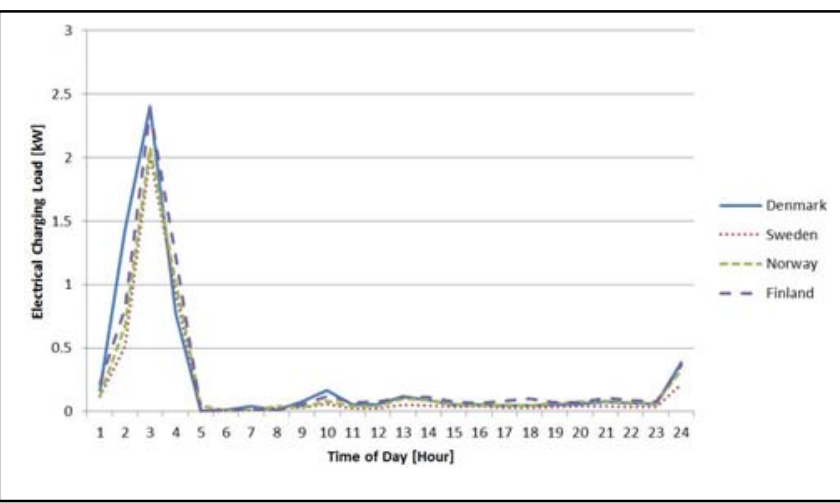

Figure 7. Average Load with Spot Price Based Charging on Weekdays.

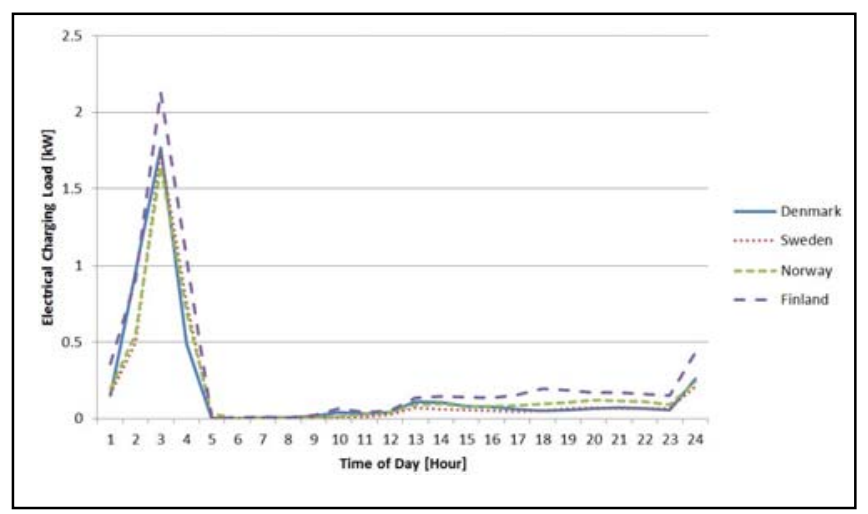

Figure 8. Average Load with Spot Price Based Charging on Weekends

TABLE III shows the peak charging demand of the EVs with spot price based charging in the Nordic area.

TABLE III. PEAK Charging DeMAND of SPOT PRICE BASED CHARGING

\begin{tabular}{|c|c|c|c|c|}
\hline & Denmark & Sweden & Norway & Finland \\
\hline Weekdays & 2.40 & 2.01 & 2.07 & 2.37 \\
\hline Weekends & 1.76 & 1.74 & 1.64 & 2.13 \\
\hline
\end{tabular}

\section{DISCUSSIONS}

\section{A. Demand Scenario with High Penetration Level of EVs}

The charging load of EVs is not negligible to the grid when there is a high EV penetration level. The results of the charging analysis in Section III show that the load of EV charging has different patterns with different charging schemes, which results in different impacts on the total system demand. The EV charging load curves of weekdays with different charging patterns combined with the original electric load for a $50 \%$ penetration scenario are shown from Figure 9 to Figure 12.

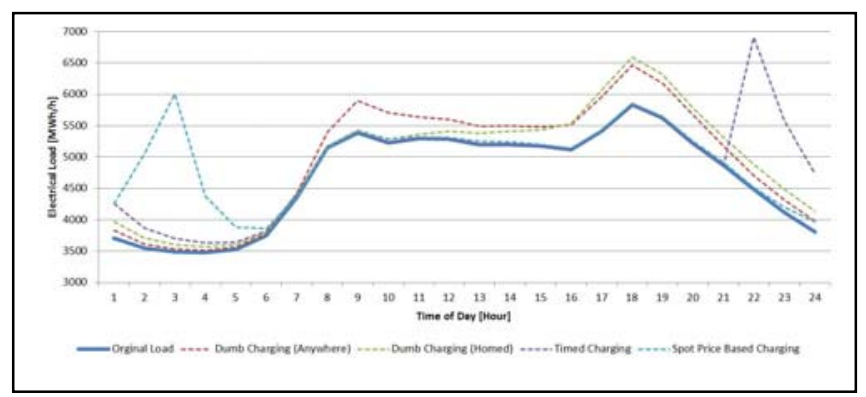

Figure 9. Electric Load with 50\% EV Penetration Scenario in Denmark.

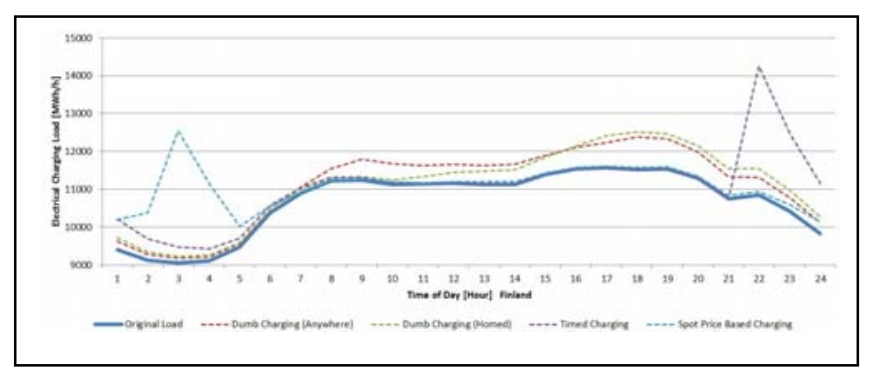

Figure 10. Electric Load with 50\% EV Penetration Scenario in Finland.

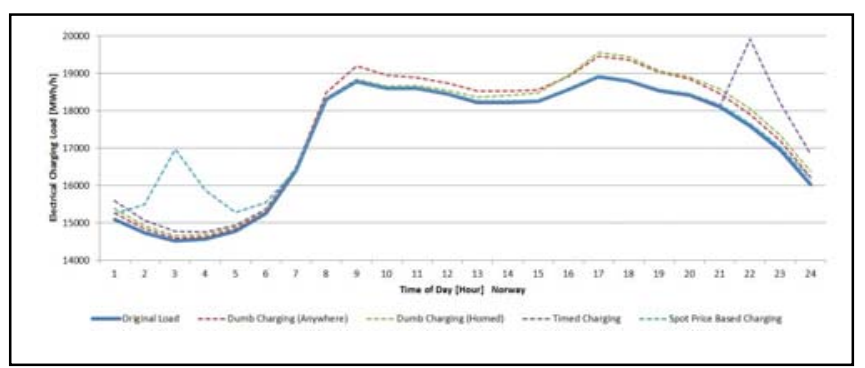

Figure 11. Electric Load with 50\% EV Penetration Scenario in Norway.

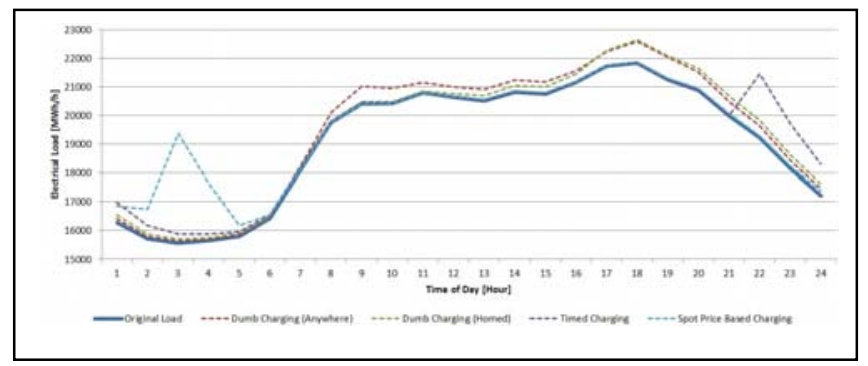

Figure 12. Electric Load with 50\% EV Penetration Scenario in Sweden.

In the dumb charging cases, the peak charging load overlaps the peak hours of the original load in the evening during weekdays, which will stress the electric power system. However, a worse case happens in the timed charging scenario. Although the charging begins after 21:00 pm when 
the original electric load starts to decrease, the spike of the EV charging load is so steep that it results in a similar spike in the total electric load. The spot price based charging, to some extent, shifts the majority of the charging demand to the low demand period of the electric power grid at night. Nevertheless, most of the charging congregates in the hours of low electric spot prices and generates the high electrical load in the corresponding time period as a result.

\section{B. Impacts of the Charging Rate}

It is shown that the system capacity problems may arise from the power demand during the peaks of the charging load. With the increasing short charging time requirement, the EV charging rate needs to be increased accordingly. Therefore, it tends to have higher peaks in the charging load. In order to investigate the impact of the charging rate on the peak load, different charging rates are applied in the Danish EV charging scenarios on weekdays. The results are shown in Figure 13. As shown in the figure, the peak charging load increases with higher charging load. The dumb charging cases have much less steep curves than the cases for timed charging and spot price based charging.

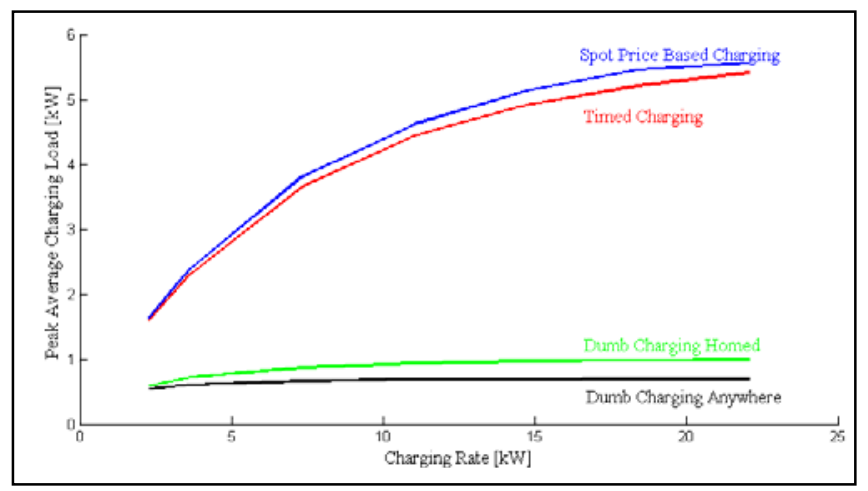

Figure 13. Peak Demand of the EV Charging with Different Charging Rates.

\section{CONCLUSIONS}

This paper provides an overview of the charging load with large scale deployment of EVs in the Nordic area. The EV charging loads of Denmark, Finland, Norway and Sweden have similar patterns. The average energy consumption of EV charging is not very high. However, the peak EV charging load is considerable if there is a high EV penetration level. With the dumb charging scenario, the peak load of the charging overlaps the peak hours of the original electric load, which will further stress the grid. The difference between the charging patterns on weekdays and weekends is notable. With the timed charging and spot price based charging scenarios, the charging load is shifted to the relatively low-demand period. There are a few factors which are not considered, such as the stochastic characteristics of the driving patterns, the impact of the temperature on the performance of the EVs and the interplay of the EV charging load and the electricity market. Further investigation will be done in these related areas in order to achieve better understanding of the impact of the EV charging load on the electric power system.

\section{REFERENCES}

[1] Nordic Energy Research. (2011, Oct.). Sustainable Energy Systems 2050. [Online]. Available: http:// www.nordicenergy.org/programme/sustainable-energy-systems-2050/

[2] I. Graabak. (2013, Feb.). NORSTRAT decarbonisation of the Nordic electricity, transport and heating sectors 2050. [Online]. Available: http://www.sintef.no/SINTEF-Energi-AS/Xergi/Xergi-2012/Xergi20121/NORSTRAT-dekarbonisering-av-Nordens-kraft--transport-ogvarmesektor-frem-mot-2050/

[3] Jalal T. Salihi, "Energy Requirements for Electric Cars and Their Impact on Electric Power Generation and Distribution Systems," IEEE Trans. Industry Application, vol. IA-9, pp. 516-532, Apr. 1973.

[4] G. T. Heydt, "The impact of Electric Vehicle Deployment on Load Management Strategies," IEEE Trans. Power Apparatus and Systems, vol. PAS-102, pp. 1253-1259, Apr. 1983.

[5] S. Rahman, G. B. Shrestha, "An investigation into the impact of electric vehicle load on the electric utility distribution system," IEEE Trans. Power Delivery, vol. 8, pp. 591-597, Apr. 1993.

[6] J. A. P. Lopes, F. J. Soares, P. M. R. Almeida, "Identifying Management Procedures to Deal with Connection of Electric Vehicles in the Grid," in Proc. 2009 IEEE Bucharest PowerTech Conf., pp. 1-8.

[7] Z. Ma, D. Callaway, I. Hiskens, "Decentralized Charging Control for Large Populations of Plug-in Electric Vehicles: Application of the Nash Certainty Equivalence Principle," in Proc. 2010 IEEE International Conference on Control Applications (CCA) Conf., pp. 191-195.

[8] K. Shimizu, T. Masuta, Y. Ota, A. Yokoyama, "Load Frequency Control in Power System Using Vehicle-to-Grid System Customer Convenience of Electric Vehicles," in Proc. 2010 IEEE Power System Technology (POWERCON) Conf., pp. 1-6.

[9] Z. Luo, Y. Song, Z. Hu, Z. Xu, X. Yang, K. Zhan, "Forecasting Charging Load of Plug-in Electric Vehicles in China," in Proc. 2011 IEEE Power and Energy Society General Meeting, pp. 1-8.

[10] K. Qian, C. Zhou, M. Allan, Y. Yuan, "Modeling of Load Demand Due to EV Battery Charging in Distribution Systems," IEEE Trans. Power System, vol. 26, pp. 802-810, May. 2011.

[11] Z. Xu, Z. Hu, Y. Song, Z. Luo, K. Zhan, J. Wu, "Coordinated charging strategy for PEVs charging stations," in Proc. 2012 IEEE Power and Energy Society General Meeting, pp. 1-8.

[12] Y. Wang, Q. Guo, H. Sun, Z. Li, "An investigation into the impacts of the crucial factors on EVs charging load," in Proc. 2012 IEEE Innovative Smart Grid Technologies-Asia (ISGT Asia) Conf., pp. 1-4.

[13] O. Sundstrom, C. Binding, "Planning Electric-Drive Vehicle Charging under Constrained Grid Conditions," in Proc. 2010 IEEE Power System Technology (POWERCON) Conf., pp. 1-6.

[14] O. Sundstrom, C. Binding, "Flexible Charging Optimization for Electric Vehicles Considering Distribution Grid Constraints," IEEE Trans. Smart Grid, vol. 3, pp. 26-37, Apr. 2012.

[15] C. Binding, D. Gantenbein, B. Jansen, O. Sundstrom, P. B. Andersen, F. Marra, B. Poulsen, C. Traeholt, "Electric Vehicle Fleet Integration in the Danish EDISON Project - A Virtual Power Plant on the Island of Bornholm," in Proc. 2010 IEEE Power and Energy Society General Meeting, pp. 1-8.

[16] T. K. Kristoffersen, K. Capion, P. Meibom, "Optimal Charging of Electric Drive Vehicles in a Market Environment" Appl. Energy, vol. 88, pp. 1940-1948, May 2011.

[17] J, Kiviluoma, P. Meibom, "Methodology for modelling plug-in electric vehicles in the power system and cost estimates for a system with either smart or dumb electric vehicles," Energy, vol. 36, pp. 1758-1767, March 2011.

[18] A. Rautiainen, S. Repo, P. Järventausta, A. Mutanen, K. Vuorilehto, K. Jalkanen, "Statistical charging load modelling of PHEVs in Electricity Distribution Networks Using National Travel Survey Data," IEEE Trans. Smart Grid, vol. 3, pp. 1650-1659, Dec 2012

[19] Q. Wu, A. H. Nielsen, J. Østergaard, S. T. Cha, F. Marra, Y. Chen, C. Træholt, "Driving Pattern Analysis for Electric Vehicle(EV) Grid Integration Study," in Proc. 2010 IEEE Innovative Smart Grid Technologies- Europe (ISGT Europe) Conf., pp. 1-6.

[20] Q. Wu, A. H. Nielsen, J. Østergaard. (2011, Sep.). Potential Analysis for Electric Vehicle (EV) Grid Integration. [Online]. Available: http://www.edison-net.dk/Dissemination/Reports/Report_014.aspx 